\title{
The digital Plateosaurus II: An assessment of the range of motion of the limbs and vertebral column and of previous reconstructions using a digital skeletal mount
}

Heinrich Mallison

Acta Palaeontologica Polonica 55 (3), 2010: 433-458 doi: http://dx.doi.org/10.4202/app.2009.0075

Scientific literature and museum exhibits are full of explicit and implicit claims about the possible postures and motion ranges of dinosaurs. For the example of the prosauropod Plateosaurus engelhardti I assessed the motion range of limbs and vertebral column in a CAD program using a 3D virtual skeletal mount. The range of motion of the forelimb is very limited, allowing the grasping of objects placed directly ventrally and ventrolaterally of the anterior torso. The manus is adapted for grasping. The powerful fore limb can barely reach in front of the shoulder, making a quadrupedal walking cycle impractical. Only a digitigrade pose of the pes with a steeply held metatarsus is feasible, and the morphology of the stylopodium and zeugopodium indicates a slightly flexed limb posture. Hind limb protraction and retraction are limited by the pelvic architecture. The neck has significant mobility both dorsoventrally and laterally, but blocks torsion. The dorsal vertebral column is flexible to a degree similar to the neck, mainly in the anterior half, but blocks torsion totally in the anterior and posterior thirds. The anterior dorsals are similar in shape to the posterior cervicals and significantly increase the motion range of the neck. The tail is highly flexible due to its large number of elements, showing more lateral than dorsoventral mobility. These results are compared to reconstruction drawings and museum skeletal mounts, highlighting a pattern of errors specific to certain widely used reconstruction methods.

Key words: Prosauropoda, Plateosaurus, reconstruction, digital skeleton, 3D model, accuracy.

Heinrich Mallison [heinrich.mallison@mfn-berlin.de], Museum für Naturkunde - Leibniz-Institut für Evolutions- und Biodiversitätsforschung an der Humboldt-Universität zu Berlin, Invalidenstrasse 43, 10115 Berlin.

This is an open-access article distributed under the terms of the Creative Commons Attribution License (for details please see creativecommons.org), which permits unrestricted use, distribution, and reproduction in any medium, provided the original author and source are credited. 
POFig Full text $(1,379.1 \mathrm{kB})$

Forg Supplementary file (19.1 kB) 